\title{
BORRELIOSE CANINA
}

Siham Kassab , Emerson da Silva Dankar², Jair de Albuquerque Pereira ${ }^{1}$, Luiz Alexandre Brilhante Ferreira ${ }^{3}$, Marcelo Fernando Gomes Montozo ${ }^{3}$

${ }^{1}$ Mestrando no Programa de Pós-Graduação em Sanidade e Produção Animal Sustentável na Amazônia Ocidental da Universidade Federal do Acre, Rio Branco, Acre, Brasil.E-mail: sih.kassab@gmail.com

${ }^{2}$ Pós-graduando no Programa de Aprimoramento em Práticas Hospitalares e Medicina Veterinária Preventiva da Universidade Federal do Acre, Rio Branco, Acre, Brasil.

${ }^{3}$ Bacharel em Medicina Veterinária da Universidade Federal do Acre, Rio Branco, Acre, Brasil.

Recebido em: 15/05/2020 - Aprovado em: 15/06/2020 - Publicado em: 30/06/2020 DOI: 10.18677/EnciBio_2020B13

\section{RESUMO}

A doença de Lyme é uma zoonose causada por bactérias espiroquetas do complexo Borrelia burgdorferi sensu lato, que acomete mamíferos domésticos, silvestres e seres humanos. Tendo em vista a enorme relevância à saúde pública, é necessária a realização de maiores estudos e esclarecimentos acerca desta enfermidade, constituindo objeto de estudo do presente trabalho. Difundida pela América do Norte, Europa e Ásia, a borreliose é transmitida durante o repasto sanguíneo de carrapatos, principalmente do gênero Ixodes. Os caninos e equinos são as espécies domésticas com apresentações clínicas mais evidenciadas, com quadros inespecíficos apresentando alterações articulares, lesões cutâneas com eritemas, e sinais semelhantes à gripe. Para o diagnóstico são utilizadas técnicas como ELISA, Western blot, que é considerado padrão ouro de diagnóstico, reação de imunofluorescência indireta (RIFI), cultivo bacteriano, PCR e exames histopatológicos. Os principais tratamentos empregados são antibióticos, como a doxiciclina, e anti-inflamatórios não esteroidais em quadros com desenvolvimento de laminites e artrites. É de extrema importância proceder a profilaxia da borreliose através do controle de artrópodes vetores da bactéria e, em alguns países com maior incidência como os Estados Unidos, a vacinação dos animais.

PALAVRAS-CHAVE: carrapato, doença de Lyme, zoonose.

\section{CANINE BORRELIOSIS}

\begin{abstract}
Lyme disease is a zoonosis caused by spirochete bacteria of the Borrelia burgdorferi sensu lato complex, which affects domestic mammals, wild animals and humans. In view of the enormous relevance to public health, it is necessary to carry out further studies and clarifications about this disease, constituting the object of study in this study. Widespread in North America, Europe and Asia, borreliosis is transmitted during the blood meal of ticks, mainly of the genus Ixodes. Canines and horses are the domestic species with the most evident clinical presentations, with nonspecific


pictures showing joint changes, skin lesions with erythema, and flu-like signs. For diagnosis, techniques such as ELISA, Western blot, which is considered the gold standard of diagnosis, indirect immunofluorescence reaction (RIFI), bacterial culture, PCR and histopathological exams are used. The main treatments used are antibiotics, such as doxycycline, and non-steroidal anti-inflammatories in conditions with the development of laminitis and arthritis. It is extremely important to provide prophylaxis for borreliosis by controlling arthropod vectors for the bacterium and, in some countries with higher incidence, such as the United States, vaccinating animals.

KEYWORDS: tick, Lyme disease, zoonosis.

\section{INTRODUÇÃO}

A doença de Lyme, ou borreliose canina, é uma enfermidade de caráter infeccioso que acomete mamíferos domésticos, selvagens e seres humanos. Possui como agente etiológico espiroquetas do gênero Borrelia, sendo transmitidas por meio do repasto sanguíneo de carrapatos, habitualmente do gênero Ixodes.

As espécies responsáveis pela doença podem variar entre os continentes, assim como o carrapato transmissor. São bactérias com características de Gram negativa, com algumas modificações na composição da sua membrana, cuja observação é feita por meio da coloração de Giemsa e prata.

A borreliose desenvolve-se, na maior parte dos casos, de forma assintomática ou com apresentação de sinais inespecíficos. Quando não tratada, pode ocorrer disseminação das espiroquetas para outros órgãos, levando a quadros mais severos da doença.Possui grande relevância para a saúde pública, tendo em vista que é uma zoonose na qual animais domésticos e selvagens podem atuar como reservatórios no ciclo da doença.

É importante conhecer os diversos aspectos desta enfermidade emergente a fim de garantir a sanidade tanto de animais suscetíveis quanto de seres humanos, bem como ampliar a discussão e estudos referentes à doença e seus agentes etiológicos. Diante disso, o presente trabalho objetivou realizar uma revisão de literatura sobre Borreliose Canina.

\section{Histórico}

\section{REVISÃO DE LITERATURA}

A borreliose foi descoberta nos Estados Unidos em 1975, na comunidade de Old Lyme, nome pelo qual a doença ficou conhecida - Doença de Lyme - DL. Allen C. Steere a descobriu quando o mesmo investigava alguns casos de enfermidades, que sugeriam Artrite Idiopática Juvenil, decorrentes de mordidas de carrapatos e posteriormente davam origem a lesões no tecido cutâneo, denominadas eritema migratório (YOSHINARI et al., 2010).

Somente em 1982, Willy Burgdorfer conseguiu isolar o agente etiológico, dando o nome de Borrelia burgdorferi. No entanto, na Europa alguns pesquisadores já tinham conhecimento acerca da doença desde as primícias do século $X X$, (YOSHINARI et al., 2010). Devido a essa descoberta o período de 1990 foi marcado por grandes estudos epidemiológicos, imunológicos e patológicos a respeito da enfermidade, sendo o agente causador considerado um dos mais investigados no mundo durante essa época (ATALIBA et al., 2007).

Uma doença com sintomatologia semelhante a DL foi descoberta nessa época, vinculada a humanos, relacionada à bactéria Borrelia lonestari, no entanto, 
esse agente foi considerado distinto quando comparado a outras espécies de Borrelia sp. (ATALIBA et al., 2007).

A partir de 1980, casos de Doença de Lyme começaram a serem relatados no Brasil, principalmente nos estados de Mato Grosso do Sul, Rio de Janeiro, Amazonas e São Paulo (ATALIBA et al., 2007).

Para o diagnóstico dos casos, utilizou-se de provas sorológicas como ELISA e Western blot, onde se fez uso de antígenos de $B$. burgdorferi sensu stricto. Em razão da existência de reações cruzadas da sorologia entre as espécies diferentes de Borrelia não se conseguiu comprovar que os casos da doença em seres humanos no Brasil era proveniente do agente que pertencia ao complexo $B$. burgdorferi sensu lato, uma vez que os testes realizados para sorologia tinham padrões de reação diferentes das demais observadas nas regiões endêmicas da doença (ATALIBA et al., 2007).

Em decorrência ao não isolamento ou identificação do agente nos seres humanos que se apresentavam doentes ou em animais silvestres, os pesquisadores denominaram de "doença de Lyme-símile" (DLS), para designar a enfermidade que havia sido diagnosticada no Brasil (BASILE et al., 2017).

Anteriormente considerava-se que o Brasil não possuía condições epidemiologicamente favoráveis para a implantação do agente associada a baixa ocorrência de carrapatos da espécie Ixodes aragaoi, considerado principal vetor da doença (ATALIBA et al., 2007). Entretanto, estudos sugerem que a Borrelia sp. é identificada em outras espécies de carrapatos nas mais diferentes regiões do mundo. Apesar de ser o vetor mais frequente, os carrapatos do gênero Ixodes não são os únicos a albergarem a bactéria, podendo ser encontrada nos gêneros Dermacentor sp., Amblyomma sp. e Rhipicephalus sp., responsáveis por parasitar animais silvestres, domésticos e humanos (YOSHINARI et al., 2010; QUEIROZ et al., 2018).

\section{Etiologia}

A doença de Lyme é uma enfermidade infecciosa transmitida, normalmente, por carrapatos do gênero Ixodes (MIZIARA et al., 2018). O agente infeccioso é identificado como Borrelia burgdorferi sensu lato, este grupo conglomera até 18 espécies de microrganismos. Este gênero de bactérias está classificado na ordem Spirochaetales, família Spirochetaceae, mesma família da Leptospira e Treponema (KRUPKA et al., 2007).

Estes microrganismos unicelulares apresentam-se em forma de espiral, com uma parede celular de 10-30 m de comprimento e 0,2-0,3 m de diâmetro (Figura 1). Apresentam por volta de 7-14 flagelos em cada extremidade, conferindo mobilidade. Diferente de outras bactérias, a parede celular deste agente não define sua forma, esta característica é determinada pelos flagelos. O envelope celular possui uma composição similar às bactérias gram negativas, não demonstrando a presença de lipopolissacarídeo 38 e excesso lipoproteínas na membrana celular externa (KRUPKA et al., 2007). 
FIGURA 1 - Espiroqueta Borrelia burgdorferi, causadora da doença de Lyme, corada com Syto 9 e visualizada por microscopia fluorescente.

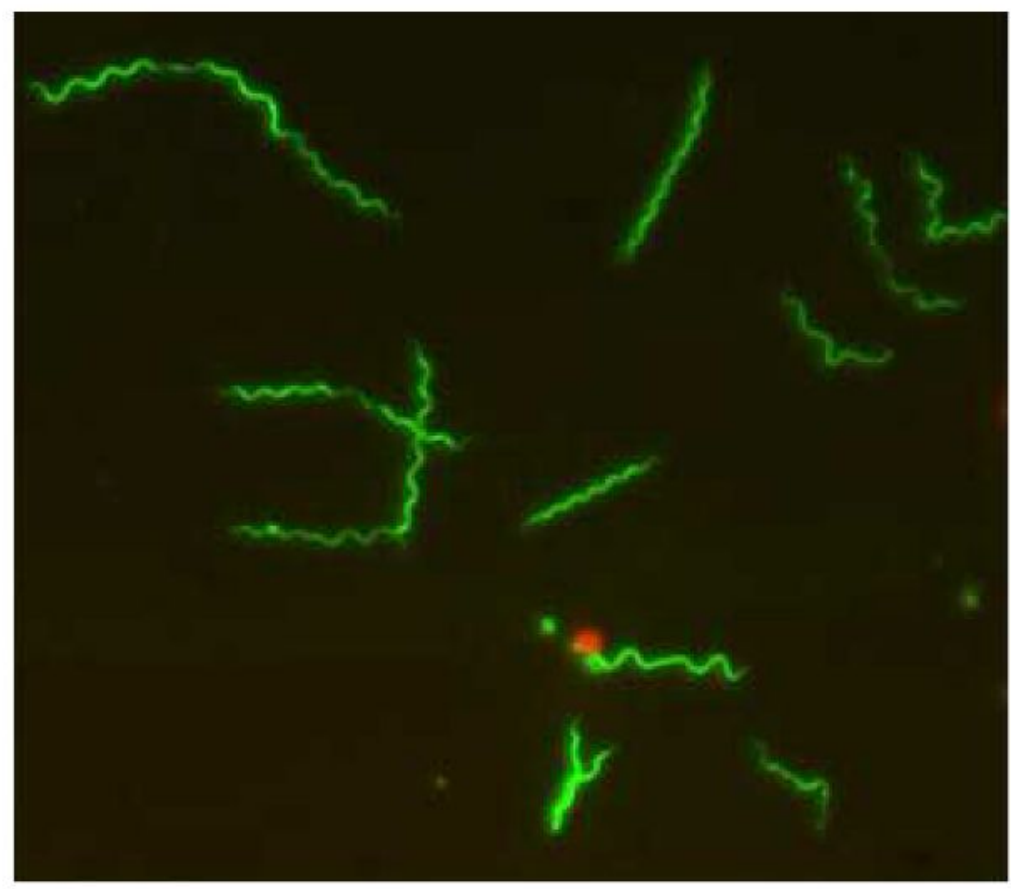

Fonte: MURRAY; SHAPIRO (2010).

Os glicolipídeos presentes na membrana da Borrelia acarretam na produção, em cobaias, de anticorpos específicos que estão ligados a reação cruzada com os gangliosídeos, tendo potencial envolvimento na patogenia da neuroborreliose, na qual há comprometimento neurológico (HOSSAIN et al., 2001; POZSGAY; KUBLERKIELB, 2007).

As bactérias deste gênero crescem em meios com uma quantidade de oxigênio reduzida e temperatura por volta de $33^{\circ} \mathrm{C}$ (RUZIĆ-SABLJIĆ et al., 2017). Essas espiroquetas podem ser cultivadas no meio líquido modificado de BarbourStonner-Kely (BSK), neste estão acrescidos e retirados alguns ingredientes para que posso ocorrer o crescimento bacteriano (KRUPKA et al., 2007).

Há no mercado um meio padronizado denominado de BSK-H. Esse cultivo pode ocorrer em meio solidificado, pela adição de agarose, possibilitando o isolamento de colônias específicas e selecionar diversas variantes genéticas, dado que determinadas estirpes não crescem em meio sólido (RUZIĆ-SABLJIĆ et al., 2017). A visualização destes microrganismos realiza-se por meio da coloração de Giemsa e prata e utilização da microscopia de campo escuro (LEVINSON, 2016).

Há uma doença semelhante no Brasil denominada de doença brasileira de Lyme, mesmo sendo descrita nos últimos séculos não se sabe o agente fomentador da enfermidade, pois ainda não foi possível o seu isolamento, podendo ser causada por uma determinada espécie de Borrelia ou pela Borrelia burgdorferi sensu lato geneticamente modificada (MONTANDON, 2014).

Todas as borrélias disseminam-se através de artrópodes e são patogênicas para animais domésticos, pássaros, roedores e ser humano. As espécies $B$. recurrentis e $B$. duttonii infectam apenas humanos por não possuírem reservatórios na natureza, o restante das espécies deste gênero são perpetuadas na natureza por meio do ciclo que envolve animais selvagens e carrapatos (TRABULSI; ALTERTHUM, 2008) 


\section{Epidemiologia}

A Doença de Lyme é uma borreliose que afeta mamíferos silvestres, domésticos e seres humanos. Os principais mamíferos silvestres portadores são os roedores e cervídeos, que se comportam como reservatório da bactéria, pois na maioria das vezes são assintomáticos. Entre os mamíferos domésticos os principais afetados são os equinos e os cães, que tendem a apresentar a manifestação clínica da doença (PARRY, 2016).

A Borreliose Canina associada à Doença de Lyme está distribuída principalmente no hemisfério norte, tendo como principais continentes afetados a América do Norte, com destaque para os Estados Unidos, Europa e Ásia (MIZIARA et al., 2018).

Entre as espécies que compreendem o gênero Borrelia, a doença está predominantemente associada a infecções por $B$. burgdorferi e, em menor escala, as espécies $B$. garinii e $B$. afzelii, sendo as duas últimas específicas do continente europeu (YOSHINARI et al., 2010).

Diferentemente do que ocorre no hemisfério norte, a Borreliose Canina no Brasil não está relacionada com a Doença de Lyme e sim com uma afecção similar, que foi batizada como Doença de Lyme-símile. Apesar de semelhantes estas doenças apresentam algumas divergências quanto à sintomatologia. Além disso, até o presente momento a mesma é considerada assintomática para mamíferos diagnosticados no país, diferentemente do que ocorre nos Estados Unidos, Europa e Ásia em que os cães afetados tendem a ter manifestações clínicas (YOSHINARI et al., 2010).

A etiologia da Doença de Lyme-símile ainda é desconhecida uma vez que pesquisadores não têm obtido êxito no isolamento do agente causador, porém acredita-se que seja uma variação da Borrelia burgdorferi, pois em exames sorológicos foram detectados a presença de anticorpos anti-Borrelia burgdorferi em seres humanos com apresentação clínica semelhante à da Doença de Lyme (YOSHINARI et al., 2010).

Apesar de não haver constatação de animais sintomáticos para Borreliose no Brasil, a presença de anticorpos anti-Borrelia burgdorferi tem sido relatada em diversas pesquisas epidemiológicas, especialmente em cães (MIZIARA et al., 2018).

Cordeiro et al. (2012) relataram uma prevalência de $52,56 \%$ de animais positivos para a presença de anticorpos anti- $B$. burgdorferi em pesquisa realizada com 293 cães no município de Seropédica, Rio de Janeiro, submetidos a teste de ELISA indireto, assim como Montandon et al. (2014) que em estudo realizado nos municípios de Santa Cruz do Escalvado e Pinto D'água em Minas Gerais encontraram uma prevalência de $9 \%$ de animais positivos em 224 cães também submetidos a ELISA indireto, demonstrando que, exceto pela hipótese de reação cruzada, existem espécies do gênero Borrelia circulantes entre os mamíferos brasileiros.

A transmissão da Borreliose Canina ocorre através da inoculação do agente por vetores. Os vetores são os carrapatos do gênero Ixodes, especialmente o Ixodes ricinus no hemisfério norte e lxodes loricatus no Brasil, contudo as infecções em animais domésticos e nos seres humanos em território nacional parecem ter uma maior ligação com o Amblyomma cajennenses (YOSHINARI et al., 2010; PARRY, 2016). Outro modo de transmissão possível, porém menos recorrente é a transmissão vertical em cadelas (SEIXAS et al., 2011).

A transmissão para os carrapatos, por sua vez, é transestadial onde estes hematófagos adquirem a bactéria durante a alimentação em qualquer um dos 
estádios intermediários, com a persistência da bactéria até a evolução ao próximo estágio do artrópode (SEIXAS et al., 2011).

O ciclo evolutivo do carrapato compreende a 4 estágios: Ovos, larvas, ninfas e adultos. A partir da eclosão dos ovos, cada estágio necessita de um único hospedeiro para o repasto sanguíneo. As larvas e ninfas permanecem de 2 a 4 dias realizando a alimentação em pequenos mamíferos ou eventualmente em aves - o que garante a ingestão de uma quantidade suficiente de bactérias para ocasionar a posterior infecção - e após esse período as mesmas abandonam o hospedeiro, desenvolvem-se (em tempo variável de acordo com a espécie e sazonalidade) para o estágio posterior, adquirindo um novo hospedeiro após este desenvolvimento e infectando-o - caso o hospedeiro anterior fosse portador da Borrelia sp. - durante o novo ciclo alimentar (SEIXAS et al., 2011; PARRY, 2016).

\section{Patogenia}

A infecção pela $B$. burgdorferi não ocorre imediatamente após o início do repasto dos carrapatos. Estima-se que a mesma se inicie em cerca de $48 \mathrm{~h}$ após 0 início do parasitismo e, enquanto isso haja uma multiplicação das bactérias no interior do artrópode com posterior migração para as glândulas salivares do mesmo (PARRY, 2016).

Os processos que ocorrem no interior dos carrapatos antes da infecção em mamíferos são facilitados pela expressão de uma série de proteínas de superfície externas denominadas Osp. As principais proteínas expressas são a OspA que está associada a adesão da bactéria em células-alvo e a OspC que facilita a migração da mesma para as glândulas salivares. Acredita-se que a alta variabilidade genética destas espiroquetas permita mudanças estruturais nestas proteínas auxiliando na adequação ao mamífero hospedeiro, bem como penetração em diversas estruturas orgânicas e evasão do sistema imune (NÚNCIO; ALVES, 2014; MEGID et al., 2016).

Após a inoculação ocorre a multiplicação local com aparecimento de eritema migratório, geralmente presente em humanos (Figura 2). A bactéria passa por um período de incubação que dura de uma a cinco semanas e em seguida ocorre a disseminação hematógena (HU, 2016; MEGID et al., 2016).

FIGURA 2 - Eritema migratório em paciente humano.

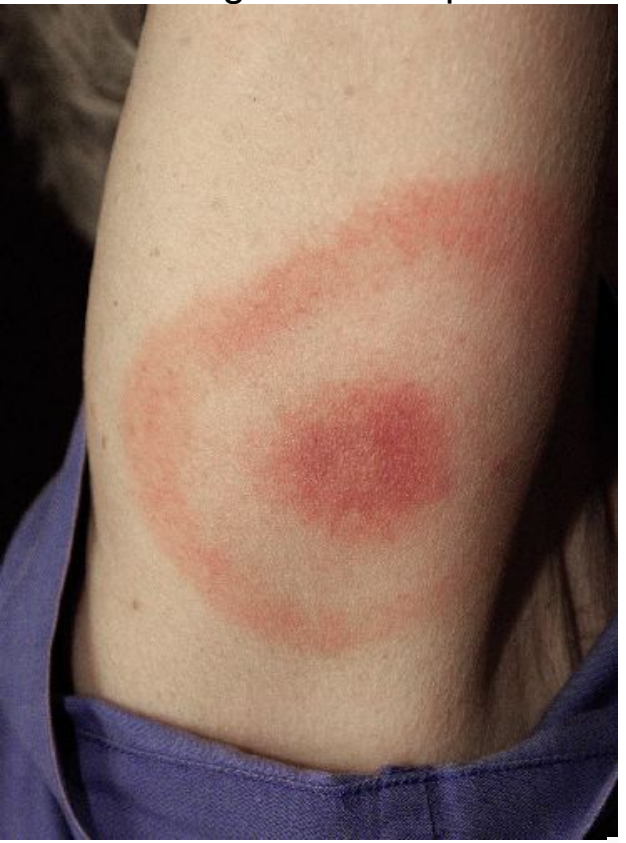

Fonte: BORCHERS et al. (2015). 
Acredita-se que após a disseminação pela circulação sanguínea haja migração da bactéria para tecidos intersticiais, especialmente os que são ricos em colágeno, onde se estabelecem e posteriormente migram para outros locais como tecido nervoso, renal, cardíaco, musculatura e articulações causando surtos agudos de meningite, encefalite, endocardite, glomerulonefrite e claudicações, dentre outros problemas (NÚNCIO; ALVES, 2014; PARRY, 2016).

O fim da fase aguda parece estar associado com a ativação de Linfócitos $B$ após cerca de três a seis semanas culminando com um aumento da produção de IgM onde a doença pode evoluir para cura ou dar início a manifestação tardia da infecção onde as bactérias podem permanecer em latência por longos períodos manifestando-se em picos de imunossupressão apresentando problemas contínuos de prognóstico reservado (NÚNCIO; ALVES, 2014).

\section{Sinais Clínicos}

Ao contrário dos humanos, grande parte dos cães infectados com a doença de Lyme, quase não apresentam sinais, em torno de $5 \%$ dos animais apresentam algum tipo de sintomatologia ligada a $B$. burgdorferi. Os sinais inespecíficos na forma aguda incluem hipertermia, apatia, depressão, anorexia, linfadenomegalia, diarreia, conjuntivite, vômitos, córnea opaca e claudicação. A claudicação inicia-se, geralmente, no membro mais próximo à picada do carrapato e se não for tratada pode evoluir para poliartrite não erosiva crônica (PARRY, 2016; BORYS et al., 2019; STILLMAN et al., 2019).

Quando não realizado tratamento, pode ocorrer disseminação para o fígado, meninges, coração, líquido cefalorraquidiano e rins. Os sinais da miocardite incluem redução da contratilidade miocárdica, arritmias ventriculares, insuficiência cardíaca congestiva e síncope. Os sintomas da neuroborreliose estão ligados a alterações comportamentais, agressividade e convulsões (NELSON; COUTO, 2015; REBMAN; ACOUTT, 2020).

A artrite de Lyme ocorre em metade dos indivíduos não tratados, gera artropatia crônica erosiva, artrite e fibromialgia, que pode permanecer mesmo após o tratamento e cura, culminando na síndrome pós Lyme (REBMAN; ACOUTT, 2020). $\mathrm{Na}$ forma cutânea é possível visualizar urticária, dermatite úmida e eritema (Figura 3) (RAMSEY; TENNANT, 2010).

FIGURA 3 - Canino com doença de Lyme apresentando eritema.

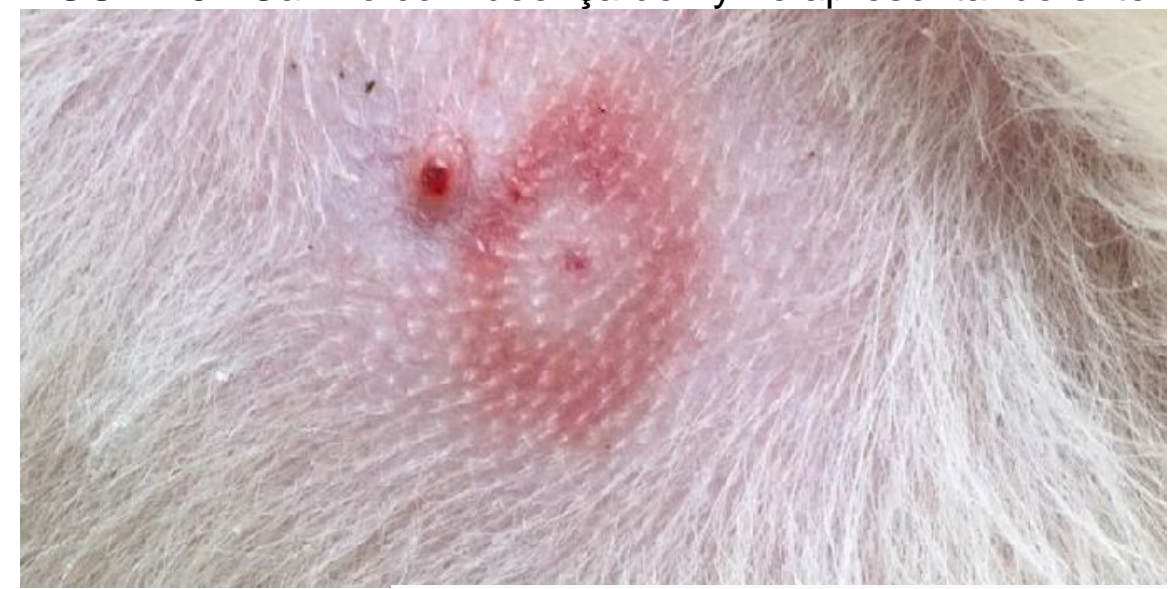

Fonte: Página de Debs Nellie Bean e Sadie Bug no Instagram ${ }^{1}$. 
Com o avanço da doença, pode ocorrer a nefrite de Lyme, termo ligado a grave nefropatia, causada pela deposição de imunocomplexos nos rins, levando a perda de proteínas associada a insuficiência renal. Este quadro ocorre em $5 \%$ a $10 \%$ dos cães infectados, possui um curso progressivo e, em muitos casos, fatal (BORYS et al. 2019).

\section{Achados de Patologia Clínica}

Os resultados obtidos nas análises clínicas estão diretamente relacionados com a forma da manifestação da borreliose canina, que pode se manifestar principalmente no sistema articular, neural e renal (BORYS et al., 2019).

Em casos de acometimento neurológico em humanos o líquido cefalorraquidiano (LCR) pode apresentar um discreto aumento da concentração de proteínas concomitante com um quadro pleocitose, porém este quadro ainda não tem sido identificado de maneira sólida em cães (HALPERIN, 2015).

Canídeos com quadros agudos ou crônicos de artrite tendem a apresentar resultados normais de eritrograma e leucograma. A bioquímica sérica também apresenta valores normais, tendo como possível alteração a elevação da creatina quinase $(\mathrm{CK})$, podendo esta alteração ligar-se à presença de lesões musculares esqueléticas resultantes da dificuldade de locomoção decorrente da inflamação articular. Os achados relacionados a mesma resumem-se especialmente a alteração no líquido sinovial, com a presença de infiltrado inflamatório, composto quase que em sua totalidade por neutrófilos e aumento da concentração das proteínas gerando aspecto turvo (CRIVELLENTI; BORIN-CRIVELLENTI, 2015; GREENE et al., 2015; PEREIRA et al., 2018).

Em casos de acometimento renal a urinálise pode demonstrar a presença de hemácias, proteína e hemoglobina na urina além da presença de cilindros acompanhados da diminuição da densidade urinária e glicosúria caso ocorra comprometimento tubular. O hemograma revela diminuição de todas as linhagens de células sanguíneas, com leucopenia, trombocitopenia e anemia arregenerativa. Alterações no perfil bioquímico também podem ser observadas e dentre elas é possível destacar hipoalbuminemia, hiperbilirrubinemia, azotemia, aumento de fósforo e potássio dentre outras (BORYS et al., 2019).

\section{Achados de Necropsia e Histopatologia}

Observa-se na necropsia de caninos severamente acometidos um derramamento do líquido sinovial, com ampliação da superfície articular, consequente principalmente da artrite desencadeada pela doença com a presença de fibrinas e neutrófilos (Figura 4) (MEGID et al., 2016). 
FIGURA 4 - Histologia de cápsula articular do cotovelo de um cão 155 dias pós infecção por B. burgdorferi contendo exsudato de fibrina misturado com leucócitos (principalmente neutrófilos) no espaço articular (JS). HE. 105x.

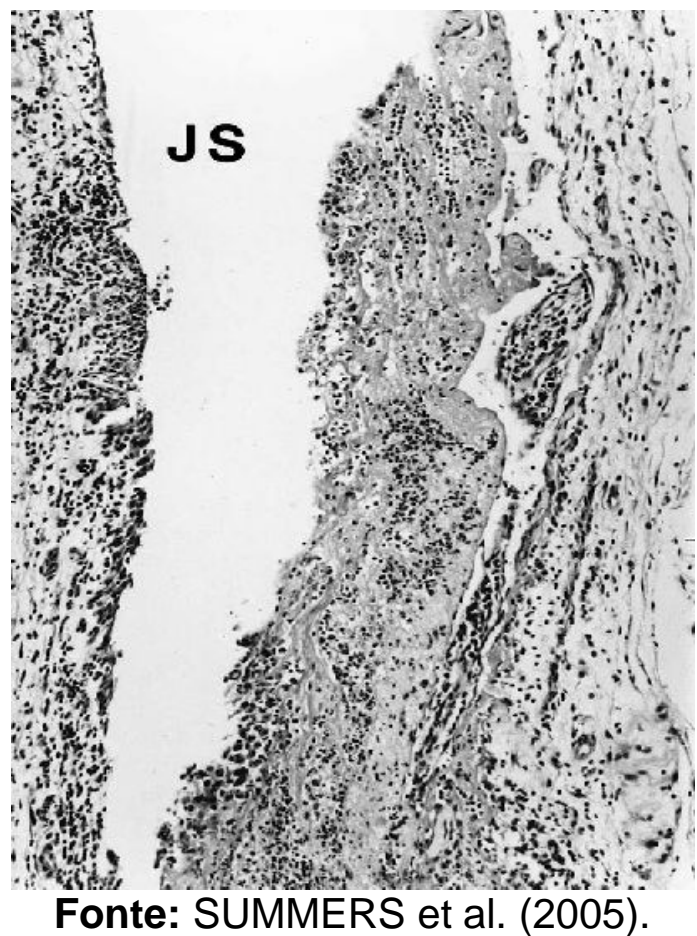

Microscopicamente pode-se ainda, observar na histologia infiltrado inflamatório com grande número de linfócitos e neutrófilos, e fragmentos de espiroquetas, alterações decorrentes da lesão renal, geralmente associados a quadros de proteinúria, azotemia, hematúria, piúria e cilindros como a glomerulonefrite com necrose nos túbulos renais e regeneração, nefrite intersticial, adesão da cápsula de bowman, proliferação mesengial, fibrose pericapsular, com focos de degeneração e necrose (SOARES et al., 2000; MEGID et al., 2016).

É possível ainda, verificar a presença de linfadenomegalia e, como menos frequência há uma formação e consequente observação da degeneração hepática, meningoencefalite e esplenomegalia durante a necropsia (MEGID et al., 2016).

\section{Diagnóstico}

O diagnóstico da Doença de Lyme deve ser feito com base no exame clínico, considerando dados epidemiológicos e exames laboratoriais, dentre eles a microscopia, cultura e isolamento bacteriano, histopatologia, imunohistoquímica, ensaio imunoenzimático indireto (ELISA), reação de imunofluorescência indireta (RIFI), Western blot e PCR (ALVIM et al., 2005; BORCHERS et al., 2015).

O exame direto consiste na visualização do agente etiológico, por meio de lâminas com amostras clínicas (Figura 5) ou material resultante do cultivo microbiológico na microscopia de campo escuro ou contraste de fase. No caso da Doença de Lyme destaca-se a baixa espiroquetemia em caninos e equinos, podendo tornar insuficiente a amostra sanguínea para detecção microscópica e dificultar o cultivo, todavia, o material pode ser suficiente para o preparo de tecidos após a coloração (TRABULSI; ALTERTHUM, 2008). 
FIGURA 5 - Esfregaço sanguíneo com a presença de uma espiroqueta ao centro.

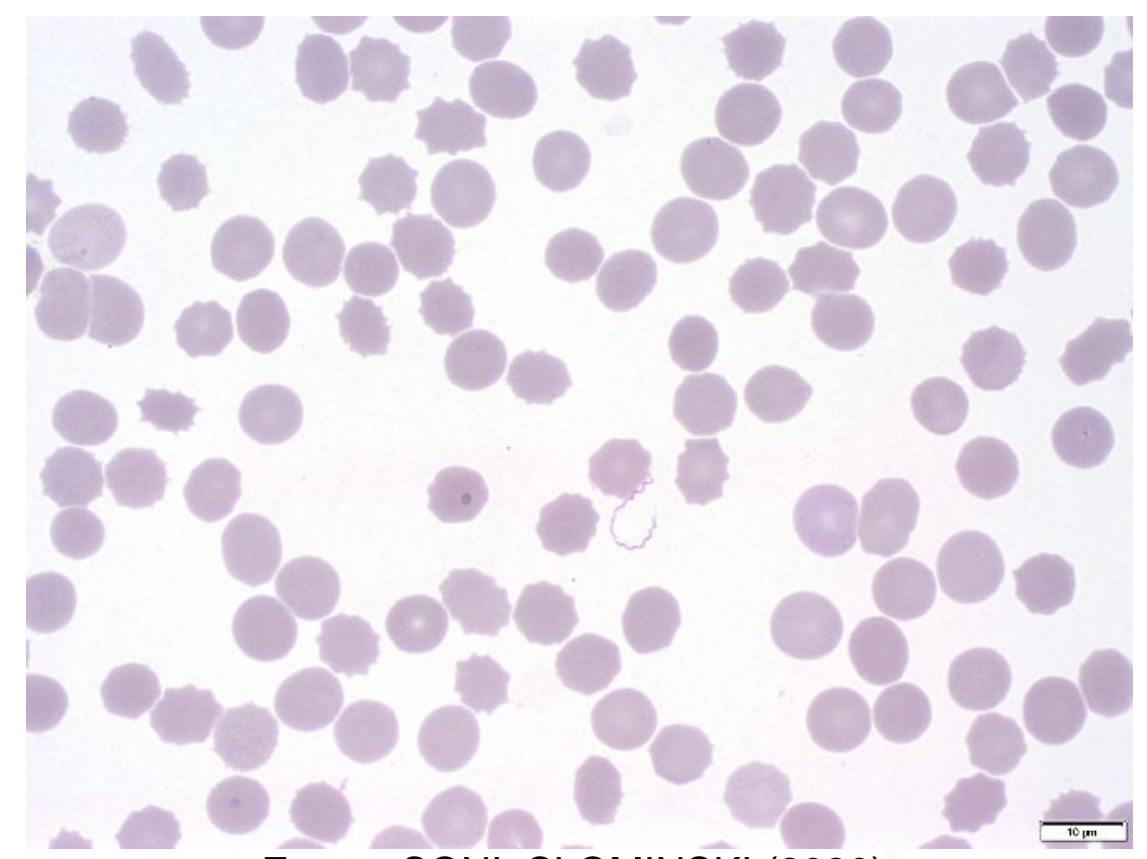

Fonte: SONI; SLOMINSKI (2020).

A utilização do cultivo e isolamento do agente causador da Doença de Lyme são técnicas mais comuns para estudos e pesquisas científicas. O cultivo possui alta especificidade, porém baixa sensibilidade, especialmente nas fases tardias da enfermidade. É realizado com amostras provenientes do carrapato, como saliva e hemolinfa, ou soro, outros fluidos corporais e tecidos do animal infectado no meio seletivo Barbour-Stoenner-Kelly (BSK), a aproximadamente $33^{\circ} \mathrm{C}$, podendo demorar de 5 dias, até semanas a meses, a depender da estirpe (GALO et al., 2009).

$O$ microrganismo $B$. burgdorferi possui elevada exigência nutricional e um crescimento extremamente fastidioso, com tempo de geração celular entre 10 e 12 horas, tornando difícil seu cultivo e levando a diversas limitações para realização deste tipo diagnóstico. Nota-se também que as amostras cultivadas rapidamente perdem seus fatores de virulência, que são lipoproteicos e alguns, como OspA, OspB e OspD, estão presentes nos plasmídeos, impossibilitando o prosseguimento dos estudos acerca dos fatores de virulência da bactéria (TRABULSI; ALTERTHUM, 2008).

Em razão da baixa carga bacteriana nas amostras, os testes sorológicos representam os principais recursos utilizados rotineiramente para o diagnóstico. Entre eles os mais utilizados são o RIFI e ELISA, que detectam anticorpos contra Borrelia sp., onde são considerados positivos, em ambos os testes no caso dos caninos, títulos superiores a 64 (MEGID et al., 2016).

É possível realizar o diagnóstico através de tecnologia ELISA com o teste rápido SNAP 4DX (IDEXX Laboratories) que é comercializado para detecção de anticorpos de Ehrlichia spp., Anaplasma spp., Borrelia burgdorferi e antígenos de Dirofilaria immitis. Para a reação de $B$. burgdorferi é utilizado o peptídeo $\mathrm{C6}$, o qual detecta anticorpos de uma lipoproteína de superfície do agente com sensibilidade de 94,1\% e especificidade de 96,2\% (IDEXX, 2016; HERRIN et al, 2017; EVASON et al, 2019). O'Connor et al. (2004) verificaram que o peptídeo C6 não possui reação cruzada com outras espécies de Borrelia encontradas nos Estados Unidos, bem como não apresenta reação aos anticorpos vacinais para Doença de Lyme. 
A ocorrência de resultados falso-negativos e falso-positivos é frequente para o diagnóstico. Tratando-se de métodos sorológicos, como ELISA, o falso-negativo pode se dar na fase inicial da infecção, no qual o organismo ainda não produziu resposta imune específica. Enquanto que falsos-positivos podem ocorrer pela detecção de anticorpos, mesmo o animal recuperado clinicamente há meses ou anos, ou seja, sem infecção ativa pela Borrelia burgdorferi (KUČEROVÁA et al., 2019).

Em casos inconclusivos ou positivos é recomendado realizar o Western Blot, que é considerado o padrão ouro (gold standard), apesar de apresentar limitações relacionadas ao custo, requerendo equipamentos caros e antígenos específicos (MEGID et al., 2016).

Em virtude da baixa especificidade podem ocorrer reações cruzadas, o que corrobora que o diagnóstico deve sempre ser feito associando os elementos necessários: manifestação clínica, epidemiologia, anamnese e exames laboratoriais. Devem ainda ser consideradas as falhas que podem ocorrer nos testes, bem como falsos positivos e falsos negativo (HALPERIN, 2015).

Por ser um teste molecular, a reação em cadeia da polimerase (PCR) é sensível e pode detectar até mesmo baixos números de microrganismos, avaliando apenas a presença do material genético. Através da PCR pode-se evitar reações cruzadas com outras espécies por este consistir em um exame espécie-específico (BORCHERS et al., 2015).

De acordo com Kučerováa et al. (2019), a PCR apresenta maior sensibilidade quando comparada ao cultivo microbiológico para a detecção de Borrelia sp. Em seu estudo conseguiram encontrar o DNA do agente através do cultivo em uma amostra de pequenos mamíferos, enquanto que por meio da PCR identificaram em sete amostras. É importante ressaltar que a microscopia e o cultivo não são métodos comuns rotineiramente e possuem menor sensibilidade quando da ocorrência de manifestações extracutâneas.

Há ainda variação da sensibilidade dependendo de fatores como o alvo da reação de PCR e a origem da amostra. Falsos resultados na reação em cadeia da polimerase ocorrem em situações como infecções agudas, no caso de falsosnegativos, e em falsos-positivos pode haver a presença de DNA de bactérias já mortas (BORCHERS et al., 2015; KUČEROVÁA et al., 2019).

\section{Diagnóstico Diferencial}

Sendo uma doença com sinais inespecíficos como alterações no tecido cutâneo, inflamação articular e manifestações, por vezes, semelhantes às da gripe, pode ser confundida com diversas doenças. Requer-se, portanto, uma diferenciação através da comparação a enfermidades com manifestações clínicas comuns ou semelhantes, entre as quais estão as artrites inflamatórias de caráter não erosivo, que apresentam sintomatologia semelhante no aparelho articular, o lúpus eritematoso, caracterizado por dores nas articulações, febre e manchas na pele, a hemartrose, que também acomete as articulações e ganha evidência pela presença de sangue no espaço articular, além da artrite do Akita, a febre do Sharpei e doenças infecciosas, por exemplo, a Febre Maculosa das Montanhas Rochosas que pode causar manifestação de febre, cefaleia e lesões cutâneas (BARR; BOWMAN, 2010). Considera-se também no diagnóstico diferencial doenças causadas por outras espiroquetas e àquelas transmitidas por vetores hematófagos como erliquiose, babesiose, anaplasmose e leishmaniose (MURRAY; SHAPIRO, 2010). 


\section{Conduta Terapêutica}

É necessária realização de terapia de suporte para cada caso, inclusas as alterações renais e quadros de poliartrites, comuns nessa enfermidade. $O$ tratamento da causa de base, como em infecções causadas por bactérias, é realizado com o uso de antibióticos, existindo uma gama considerável quanto aos fármacos utilizados (CRIVELLENTI; BORIN-CRIVELLENTI, 2015).

A doxiciclina ou a minociclina são consideradas fármacos de eleição, principalmente em função de sua característica lipoproteica, possibilitando desse modo grande penetração nos tecidos, no entanto, possui efeitos adversos especialmente para cães jovens, causando tingimento dos dentes, assim como outras tetraciclinas (ARVIKAR; STEERE, 2015; WRIGHT, 2016; CASKEY et al., 2019). Segundo Littman et al. (2018) a minociclina possui melhor absorção sem ingestão de alimentos, dessa forma indica-se sua administração antes do fornecimento da ingesta.

Além disso, fármacos como a azitromicina, ampicilina, penicilina G, ceftriaxona, amoxicilina, eritromicina, cefotaxima e cloranfenicol vem sendo usadas no tratamento de canídeos e até mesmo de humanos. Por outro lado, antibióticos como, rifampicina, a fluoroquinolonas e aminoglicosídeos tem se mostrado ineficazes ao tratamento da $B$. burgdorferi, em função da resistência desenvolvida por esses microrganismos (BARR; BOWMAN, 2010; MEGID et al., 2016).

Para antibioticoterapia, o cloridrato de doxiciclina ou a minociclina, é administrado na dose de $10 \mathrm{mg} / \mathrm{kg}$, por via oral ou intravenosa, com intervalos de 12 ou 24 horas durante 30 a 42 dias. O uso da azitromicina deve ser feito em dose igual a $25 \mathrm{mg} / \mathrm{kg}$, por via oral, a cada 24 horas por período de 10 a 20 dias. A utilização da ceftriaxona para esta enfermidade também é feita com $25 \mathrm{mg} / \mathrm{kg}$, podendo ser administrada por via intravenosa (IV) ou subcutânea (SC), a cada 24 horas com duração de 14 a 30 dias. Também pode ser escolhida a amoxicilina, a mesma é indicada em dose de $20 \mathrm{mg} / \mathrm{kg}$, por via oral, com intervalos de 8 horas entre as administrações durante 10 a 20 dias (CRIVELLENTI; BORIN-CRIVELLENTI, 2015; LITTMAN et al., 2018).

Nas manifestações neurológicas, cardíacas ou até mesmo artríticas, pode-se utilizar a via endovenosa para a administração de penicilina $G$ ou ceftriaxona, tetraciclina e doxiciclina. A administração de glicocorticoides obtém melhoras para casos de poliartrite, que geralmente são de origem imunomediada (GRILLON et al., 2018).

Para os quadros onde há o desenvolvimento de artrites é recomendado o uso de anti-inflamatórios não esteroidais, com a finalidade de suavizar a dor e inflamação na região, podendo ainda, quando necessário, utilizar analgésicos como a gabapentina para dores neuropáticas. Casos mais graves onde há queda na perfusão renal deve-se ser feito um tratamento direcionado para a correção da falha renal com o uso de diuréticos e expansores de volume, adjuvantes terapêuticos como os inibidores das enzimas conversoras de angiotensina (IECA), ácido acetilsalicílico, dieta e, caso necessário, fluidoterapia (ARVIKAR; STEERE, 2015; LITTMAN et al., 2018).

É recomendável que seja feito a avaliação sorológica mensal, durante um semestre, em animais que já tenham realizado o tratamento e obtiveram inclusive a cura clínica, pois ainda assim pode haver recidivas (MEGID et al., 2016).

Em casos de recidiva após a antibioticoterapia faz-se necessário associar outros diagnósticos com vistas à exclusão de outras doenças concomitantes, como 
outros agentes infecciosos, doenças de caráter imunomediadas, doenças articulares ou traumas (LITTMAN et al., 2018).

\section{Controle e Profilaxia}

A maneira mais eficiente de proteger a si mesmo e ao animal da Doença de Lyme, e de diversas outras transmitidas por artrópodes é não ter contato com o ectoparasito, evitando regiões de riscos como locais que tenham florestas, parques e áreas que tenham sido desmatadas a pouco tempo. Outras maneiras como a utilização de ectoparasiticidas, podendo ser tópicos, sistêmicos ou em pó, xampus, coleiras, remoção de áreas de vegetação peridomiciliar ou manejo do ambiente para o controle do vetor também se mostram eficazes (WRIGHT, 2018).

De acordo com Krämer et al. (2020), o uso de coleiras Seresto® foi eficaz para prevenir por até 7 meses a transmissão de doenças como as causadas por Borrelia sp. e Anaplasma phagocytophilum em 100\% dos cães utilizados nos estudos. A coleira possui como princípios ativos a Imidacloprida $10 \%$ e flumetrina $4,5 \%$, através dos quais previne-se a infecção por pulgas e carrapatos e consequentemente as doenças transmitidas pelos mesmos.

Princípios ativos como sarolaner e afoxolaner também possuem ação ectoparasiticida, atuando e prevenindo infestações e fornecendo controle confiável dos parasitos. Com o uso do sarolaner, que tem velocidade de morte mais rápida contra carrapatos do gênero Ixodes spp. quando comparado ao afoxolaner, é possível observação de seus efeitos em até $24 \mathrm{~h}$ e a manutenção dos mesmos durante o intervalo de tratamento por 35 dias após a administração (SIX et al., 2016).

Outros métodos estão sendo utilizados para imunizar os animais contra a enfermidade, como a vacinação e o tratamento logo após a infecção. Dentre as vacinas disponíveis estão as de subunidades (OspA) de proteínas recombinantes ou com bacterinas da parede bacteriana. No entanto, somente em alguns países há o uso da vacinação, como nos Estados Unidos, onde é aplicada em animais jovens, com cerca de 6 a 12 semanas, realizada em duas doses, com intervalos equivalentes de 3 a 4 semanas, depois se faz a vacinação de reforço semestralmente ou anualmente. Essa vacina é de uso exclusivo para cães (STILLMAN et al., 2019).

Todavia, a vacinação usada isoladamente, sem o controle dos vetores, não é tão eficaz, devendo quando administrada ser combinada com métodos de controle estratégicos de ectoparasitas. Existem ainda inconsistências quanto à duração da imunidade em resposta à vacinação, dessa forma continuam sendo estudadas e produzidas vacinas que possam fornecer imunidade com duração e eficácia superiores (LITTMAN et al., 2018).

\section{Importância à Saúde Pública}

Os primeiros casos observados da enfermidade foram identificados em 1992, em São Paulo no município de Itapevi. Conforme foram sendo diagnosticando novos casos, foi sendo observado que no Brasil havia uma forma de borreliose de Lyme com características diferentes do hemisfério norte. Nos casos descritos no Brasil, a sintomatologia aparece com menos de um mês após a picada dos carrapatos. A faixa etária em que é observada uma maior prevalência da doença é em adultos com mais de 30 anos e crianças abaixo de 14 anos. Os sinais clínicos variam de febre, dermatite, dores nos músculos, nas articulações a até mesmos sinais cardíacos, neurológicos e oftálmicos (MEGID et al., 2016). 
Apesar de ser classificada como zoonose, tanto humanos como gatos e cães são hospedeiros acidentais do ciclo silvestre da borreliose. Os felinos e caninos, em função de não eliminarem a bactéria em grandes quantidades e por um período bem curto, acredita-se que não sejam fontes de infecção ao homem. As vacinas em humanos se mostraram eficaz, no entanto devido aos efeitos adversos não tem sido empregada (MEGID et al., 2016).

\section{CONSIDERAÇÕES FINAIS}

Ao longo dos últimos 40 anos a borreliose canina tem se estendido pelo mundo, tornando-se endêmica em alguns lugares e apresentando focos de infecção em regiões que a princípio não possuíam a doença.

O seu caráter zoonótico, as diversas manifestações clínicas apresentadas por animais e seres humanos susceptíveis, bem como a vasta gama de reservatórios naturais e potenciais vetores biológicos tornam relevante a realização de pesquisas para conhecer de maneira mais específica o ciclo dessas bactérias e sua patogenicidade a fim de evitar a disseminação da mesma, especialmente em áreas com potencial de risco, e direcionar a melhor conduta terapêutica para o tratamento desta afecção.

Ressalta-se ainda que medidas profiláticas para evitar a disseminação da doença por meio do controle dos vetores são de fundamental relevância e devem compor o manejo de cães.

\section{REFERÊNCIAS}

ALVIM, N. C.; BENTO, M. A. F.; MARTINS, L. A. Borreliose de Lyme - A doença da década. Revista Científica Eletrônica de Medicina Veterinária, v. 4, p. 1-4, 2005. Disponível

em: <http://faef.revista.inf.br/imagens_arquivos/arquivos_destaque/AdIDzCEZr4RjNj3_20 13-5-20-10-44-5.pdf>. Acesso em: 15/03/2020.

ARVIKAR, S. L.; STEERE, A. C. Diagnosis and Treatment of Lyme Arthritis. Infectious Disease Clinics of North America, v. 29, n. 2, p. 269-280, 2015. Disponível em: <https://www.ncbi.nlm.nih.gov/pubmed/25999223>. DOI: 10.1016/j.idc.2015.02.004.

ATALIBA, A. C.; RESENDE, J. S.; YOSHINARI, N.; LABRUNA, M. B. Isolation and molecular characterization of a Brazilian strain of Borrelia anserina, the agent of fowl spirochaetosis. Research in Veterinary Science, v. 83, n. 2, p. 145-149, 2007. Disponível

em: <https://www.sciencedirect.com/science/article/abs/pii/S0034528806002141>. DOI: 10.1016/j.rvsc.2006.11.014.

BARR, S. C.; BOWMAN, D. D. Doença infecciosas e parasitárias em cães e gatos: consulta em 5 minutos. Rio de Janeiro: Revinter, 2010. 640 p.

BASILE, R. C.; YOSHINARI, N. H.; MANTOVANI, E.; BONOLDI, V. N.; MACORIS, D. G. et al. Brazilian borreliosis with special emphasis on humans and horses. Brazilian Journal of Microbiology, v. 48, n. 1, p. 167-172, 2017. Disponível em: <https://www.scielo.br/scielo.php?pid=S1517-

83822017000100167\&script=sci_abstract>. DOI: 10.1016/j.bjm.2016.09.005. 
BORCHERS, A. T.; KEEN, C. L.; HUNTLEY, A. C.; GERSHWIN, M. E. Lyme disease: A rigorous review of diagnostic criteria and treatment. Journal of Autoimmunity, v. 57, p. 82-115, 2015. Disponível em: <https://www.ncbi.nlm.nih.gov/pubmed/25451629>. DOI: 10.1016/j.jaut.2014.09.004.

BORYS, M., A.; KASS, P. H.; MOHR, F. C.; SYKES, J. E. Differences in clinicopathologic variables between Borrelia C6 antigen seroreactive and Borrelia C6 seronegative glomerulopathy in dogs. Journal of Veterinary Internal Medicine, v. 33, n. 5, p. 1-9, 2019. Disponível em: <https://onlinelibrary.wiley.com/doi/full/10.1111/jvim.15586>. DOI: 10.1111/jvim.15586.

CASKEY, J. R.; HASENKAMPF, N. R.; MARTIN, D. S.; CHOULJENKO, V. N.; SUBRAMANIAN, R. et al. The Functional and Molecular Effects of Doxycycline Treatment on Borrelia burgdorferi Phenotype. Frontiers in Microbiology, v. 10, p. 111 , 2019.

Disponível

em: <https://www.frontiersin.org/articles/10.3389/fmicb.2019.00690/full>.

DOI: 10.3389/fmicb.2019.00690.

CORDEIRO, M. D.; MEIRELES, G. S.; SILVA, J. B.; SOUZA, M. M. S.; FONSECA, A. H. Soroprevalência para borrelia spp. em cães no município de Seropédica, estado do Rio de Janeiro. Revista Brasileira de Medicina Veterinária, v. 34, n. 4, p. 251-256, 2012. Disponível em: http://r1.ufrrj.br/adivaldofonseca/wpcontent/uploads/2015/10/2012-Cordeiro-MD-et-al.-2012-Soropreval\%C3\%AAnciaBorrelia-c\%C3\%A3es-Serop\%C3\%A9dica.pdf. Acesso em: 21/01/2020.

CRIVELLENTIN, L. Z.; BORIN-CRIVELLETIN, S. Casos de rotina em medicina veterinária de pequenos animais. 2 ed. São Paulo: Editora MedVet, 2015. 842 p.

EVASON, M.; STULL, J. W.; PEARL, D. L.; PEREGRINE, A. S.; JARDINE, C. et al. Prevalence of Borrelia burgdorferi, Anaplasma spp., Ehrlichia spp. and Dirofilaria immitis in Canadian dogs, 2008 to 2015: a repeat cross-sectional study. Parasites \& Vectors, v. 12, n. 64, p. 1-11, 2019. Disponível em: <https://parasitesandvectors.biomedcentral.com/articles/10.1186/s13071-019-32999>. DOI: 10.1186/s13071-019-3299-9.

GALO, K. R.; FONSECA, A. H.; MADUREIRA, R. C.; BARBOSA NETO, J. D. Frequência de anticorpos homólogos anti-Borrelia burgdorferi em equinos na mesorregião metropolitana de Belém, Estado do Pará. Pesquisa Veterinária Brasileira, v. 29, n. 3, p. 229-232, 2009. Disponível em: <https://www.scielo.br/scielo.php?script=sci_arttext\&pid=S0100736X2009000300007>. DOI: 10.1590/S0100-736X2009000300007.

GREENE, C. E. Doenças infecciosas em cães e gatos. 4. ed. Rio de Janeiro: Guanabara Koogan, 2015. 1404 p.

GRILLON, A.; SCHERLINGER, M.; BOYER, P. H.; DE MARTINO, S.; PERDRIGER, A. et al. Characteristics and clinical outcomes after treatment of a national cohort of PCR-positive Lyme arthritis. Seminars in Arthritis and Rheumatism, v. 48, n. 6, p. 
1105-1112, 2018. Disponível em: <https://www.ncbi.nlm.nih.gov/pubmed/30344080>. DOI: 10.1016/j.semarthrit.2018.09.007.

HALPERIN, J. J. Chronic Lyme disease: misconceptions and challenges for patient management. Infection Drug Resistance, v. 8, p. 119-128, 2015. Disponível em: <https://www.ncbi.nlm.nih.gov/pubmed/26028977>. DOI: 10.2147/IDR.S66739.

HERRIN, B. H.; PEREGRINE, A. S.; GORING, J.; BEALL M. J.; LITTLE, S. E. Canine infection with Borrelia burgdorferi, Dirofilaria immitis, Anaplasma spp. and Ehrlichia spp. in Canada, 2013-2014. Parasites \& Vectors, v. 10, n. 244, p. 1-9, 2017. <https://parasitesandvectors.biomedcentral.com/articles/10.1186/s13071-017-21847>. DOI: 10.1186/s13071-017-2184-7.

HOSSAIN, H. WELLENSIEK, H.-J., GEYER, R. LOCHNIT, G. Structural analysis of glycolipids from Borrelia burgdorferi. Biochimie, v. 83, n. 7, p. 683-692, 2001. Disponível

em: <https://www.sciencedirect.com/science/article/abs/pii/S0300908401012962>. DOI: 10.1016/s0300-9084(01)01296-2.

HU, L. T. Lyme Disease. Annals of Internal Medicine, v. 164, n. 9, p. 65-80, 2016. Disponível em: <https://www.ncbi.nlm.nih.gov/pubmed/27136224>. DOI: 10.7326/aitc201605030.

IDEXX LABORATORIES. SNAP 4Dx Plus Test: Test accuracy. 2016. 1 p. Disponível em: https://www.idexx.com.br/files/snap-4dx-plus-test-accuracy.pdf. Acesso em: 12/05/2020.

KRÄMER, F.; HÜSKEN, R.; KRÜDEWAGEN, E. M.; DEUSTER, K.; BLAGBURN, B. et al. Prevention of transmission of Borrelia burgdorferi sensu lato and Anaplasma phagocytophilum by Ixodes spp. ticks to dogs treated with the Seresto $\AA$ collar (imidacloprid 10\% + flumethrin 4.5\%). Parasitology Research, v. 119, p. 299-315, 2020. Disponível em: <https://link.springer.com/article/10.1007/s00436-019-063948>. DOI: 10.1007/s00436-019-06394-8.

KRUPKA, M.; RASKA, M.; BELAKOVA, J.; HORYNOVA, M.; NOVOTNY, R. et al. Biological aspects of lyme disease spirochetes: unique bacteria of the Borrelia burgdorferi species group. Biomed papers of the Medical Faculty of the University Palacky, v. 151, n. 2, p. 175-186, 2007. Disponível em: <https://europepmc.org/article/med/18345249>. DOI: 10.5507/bp.2007.032.

KUČEROVÁA, H. L.; ŽÁKOVSKÁA, A.; MARKOVÁC, J.; BÁRTOVÁC, E. Detection of antibodies to Borrelia burgdorferi s.l. in wild small mammals and sensitivity of PCR and cultivation. Veterinary Microbiology, v. 230, p. 241-243, 2019. Disponível em: $<$ https://www.ncbi.nlm.nih.gov/pubmed/30827395>.

DOI: 10.1016/j.vetmic.2019.02.004.

LEVINSON, W. Microbiologia médica e imunologia. 13. ed. Porto Alegre: McGraw-Hill, 2016. 800 p. 
LITTMAN, M. P.; GERBER, B.; GOLDSTEIN, R. E.; LABATO, M. A.; LAPPIN, M. R. et al. ACVIM consensus update on Lyme borreliosis in dogs and cats. Journal of Veterinary Internal Medicine, v. 32, n. 3, p. 887-903, 2018. Disponível em: <https://onlinelibrary.wiley.com/doi/full/10.1111/jvim.15085>.

DOI: 10.1111/jvim.15085.

MEGID, J.; RIBEIRO, M. G.; PAES, A. C. Doenças infecciosas em animais de produção e de companhia. Rio de Janeiro: Roca, 2016. 1296 p.

MIZIARA, C. S. M. G.; SERRANO, V. A. G.; YOSHINARI, N. Passage of Borrelia burgdorferi through diverse Ixodid hard ticks causes distinct diseases: Lyme borreliosis and Baggio-Yoshinari syndrome. Clinics, v. 73, p. 1-4, 2018. Disponível em: <https://www.ncbi.nlm.nih.gov/pubmed/30462754>. DOI: 10.6061/clinics/2018/e394.

MONTANDON, C. E.; YOSHINARI, N. H.; MILAGRES, B. S.; MAZIOLI, R.; GOMES, G. G. et al. Evidence of Borrelia in wild and domestic mammals from the state of Minas Gerais, Brazil. Revista Brasileira de Parasitologia Veterinária, v. 23, n. 2, p. 287-290, 2014. Disponível em: <https://www.scielo.br/scielo.php?pid=S198429612014000200287\&script=sci_arttext\&tIng=en>. DOI: $\quad$ 10.1590/S198429612014040.

MURRAY, T. S.; SHAPIRO, E. D. Lyme Disease. Clinics in Laboratory Medicine, v. $30, \quad$ n. $1, \quad$ p. 311-328, 2010. Disponível em: <https://www.ncbi.nlm.nih.gov/pmc/articles/PMC3652387/>. DOI: 10.1016/j.cll.2010.01.003.

NELSON, R. W.; COUTO, C. G. Medicina interna de pequenos animais. 5 ed. Rio de Janeiro: Elsevier, 2015. 1512 p.

NÚNCIO, M. S.; ALVES, M. J. Doenças associadas a artrópodes vetores e roedores. Lisboa: Instituto Nacional de Saúde Doutor Ricardo Jorge, 2014. 184 p.

O'CONNOR, T. P.; ESTY, K. J.; HANSCOM, J. L.; SHIELDS, P.; PHILIPP, M. T. Dogs Vaccinated with Common Lyme Disease Vaccines Do Not Respond to IR6, the Conserved Immunodominant Region of the VIsE Surface Protein of Borrelia burgdorferi. Clinical and Diagnostic Laboratory Immunology, v. 11, n. 3, p. 458462, 2004. Disponível em: <https://cvi.asm.org/content/11/3/458>. DOI: 10.1128/CDLI.11.3.458-462.2004.

PARRY, N. Canine borreliosis: epidemiology, pathogenesis, clinical signs, and diagnostics. Companion Animal, v. 21, n. 6, p. 392-397, 2016. Disponível em: $<$ https://www.researchgate.net/publication/303779616_Canine_borreliosis_epidemiol ogy_pathogenesis_clinical_signs_and_diagnostics>.

DOI: $10.12968 /$ coan.2016.21.6.323.

PEREIRA, A. B. A.; MORENO, B. F. S.; GALENO, L. S. G.; ALVES, A. M.; FONSECA, W. C. et al. Doença de Lyme em cão da raça Rottweiler: Relato de caso. PUBVET, v. 12, n. 3, p. 1-5, 2018. Disponível em: <https://www.pubvet.com.br/uploads/75c4c352f15cc712f13b11f375ad12e8.pdf>. DOI: 10.22256/pubvet.v12n3a43.1-5. 
POZSGAY, V.; KUBLER-KIELB, J. Synthesis of an experimental glycolipoprotein vaccine against Lyme disease. Carbohydrate Research, v. 26, n. 342 (3-4), p. 621626, $2007 . \quad$ Disponível em: <https://www.sciencedirect.com/science/article/abs/pii/S0008621506005283>. DOI: 10.1016/j.carres.2006.11.014.

QUEIROZ, N. A.; MASSAKI, S. H.; OLIVEIRA, J. V. M.; ALBRES, B. F.; ELISEI, C. et al. Introdução morfológica da espiroqueta Borrelia spp. no exame da hemolinfa de Rhipicephalus microplus. Brazilian Journal of Animal and Environmental Research, v. 1, n. 2, p. 414-419, 2018. Disponível em: http://www.brazilianjournals.com/index.php/BJAER/article/view/1050/914. Acesso em: 10/05/2020.

RAMSEY, I. K.; TENNANT, B. J. Manual de doenças infecciosas em cães e gatos. 1 ed. São Paulo: Roca, 2010. 320 p.

REBMAN, A. W.; AUCOTT, J. N. Post-treatment Lyme Disease as a Model for Persistent Symptoms in Lyme Disease. Frontiers in Medicine, v. 7, n. 57, p. 1-16, $2020 . \quad$ Disponível em: <https://www.frontiersin.org/articles/10.3389/fmed.2020.00057/full>. $\quad$ DOI: 10.3389/fmed.2020.00057.

RUZIĆ-SABLJIĆ, E.; MARASPIN, V.; STUPICA, D.; ROJKO, T.; BOGOVIČ, P. et al. Comparison of MKP and BSK-H media for the cultivation and isolation of Borrelia burgdorferi sensu lato. PLoS ONE, v. 12, n. 2, p. 1-11, 2017. Disponível em: <https://journals.plos.org/plosone/article?id=10.1371/journal.pone.0171622>. DOI: 10.1371/journal.pone.0171622.

SEIXAS, R.; ALHO, A. M.; GUERRA, D.; CARVALHO, L. M. Doenças Caninas de transmissão vectorial: uma picada com muitas consequências! Veterinary Medicine, v. 13, p. 18-36, 2011. Disponível em: https://www.researchgate.net/publication/230882941_Doencas_caninas_de_transmi ssao_vectorial_uma_picada_com_muitas_consequencias. Acesso em: 19/01/2020.

SIX, R. H.; YOUNG, D. R.; MYERS, M. R.; MAHABIR, S. P. Comparative speed of kill of sarolaner (Simparica ${ }^{\mathrm{TM}}$ ) and afoxolaner (NexGard®) against induced infestations of Ixodes scapularis on dogs. Parasites \& Vectors, v. 9, n. 79, p. 1-6, 2016. Disponível em: $<$ https://parasitesandvectors.biomedcentral.com/articles/10.1186/s13071-016-1307x>. DOI: 10.1186/s13071-016-1307-x.

SOARES, C. O.; ISHIKAWA, M. M.; FONSECA, A. H.; YOSHINARI, N. H. Borrelioses, agentes e vetores. Pesquisa Veterinária Brasileira, v. 20, n. 1, p. 1-19, 2000. Disponível em: $<$ https://www.scielo.br/scielo.php?script=sci_arttext\&pid=S0100736X2000000100001>. DOI: 10.1590/S0100-736X2000000100001.

SONI, A.; SLOMINSKI, A. Lyme disease. Disponível em: <http://www.pathologyoutlines.com/topic/skinnontumorlymedisease.html>. Acesso 
em: 10 jun. 2020.

STILLMAN, B. A.; THATCHER, B.; BEALL, M. J.; LAPPIN, M.; O'CONNOR, T. P. O. Borrelia burgdorferi Antibody Test Results in Dogs Administered 4 Different Vaccines. Topics in Companion Animal Medicine, v. 37, p. 1-4, 2019. Disponível em: <https://www.sciencedirect.com/science/article/pii/S1938973619300959>. DOI: 10.1016/j.tcam.2019.100358.

SUMMERS, B. A.; STRAUBINGER, A. F.; JACOBSON, R. H.; CHANG, Y.-F.; APPEL, M. J. G. et al. Histopathological Studies of Experimental Lyme Disease in the Dog. Journal of Comparative Pathology, v. 133, n. 1, p. 1-13, 2005. Disponível em: <https://www.sciencedirect.com/science/article/abs/pii/S0021997505000083>. DOI: doi:10.1016/j.jcpa.2004.11.006.

TRABULSI, L. R.; ALTERTHUM, F. Microbiologia. 15 ed. Rio de Janeiro: Atheneu, 2005. $718 \mathrm{p}$.

WRIGHT, I. UK Lyme disease: treatment and prevention. Companion animal, v. 21, n. $7, \quad$ p. 392-397, 2016. Disponível em: $<$ https://www.magonlinelibrary.com/doi/abs/10.12968/coan.2016.21.7.392?af=R>. DOI: 10.12968/coan.2016.21.7.392.

YOSHINARI, N. H.; MANTOVANI, E.; BONOLDI, V. L. N.; MARANGONI, R. G.; GAUDITANO, G. Doença de Lyme-símile brasileira ou síndrome Baggio-Yoshinari: zoonose exótica e emergente transmitida por carrapatos. Revista da Associação Médica Brasileira, v. 56, n. 3, p. 363-369, 2010. Disponível em: $<$ https://www.researchgate.net/publication/245846708_Doenca_de_lymesimile_brasileira_ou_sindrome_baggio-

yoshinari_Zoonose_exotica_e_emergente_transmitida_por_carrapatos>. DOI: 10.1590/S0104-42302010000300025. 